\title{
Efficacy of uniportal video-assisted medical thoracoscopy in the management of multiloculated pleural infections: a retrospective study
}

\author{
Amr Mounir Shoukrie
}

\begin{abstract}
Background: Pleural infection is a serious medical issue for which the appropriate management is still controversial. Complicated (multiloculated) pleural infection usually requires invasive approach.

Results: A retrospective study that aims to assess the efficacy of uniportal video-assisted medical thoracoscopy in the management of complicated (multiloculated) pleural infections. Review of the charts of 37 patients with multiloculated pleural infections who were treated by uniportal video-assisted medical thoracoscopy. There were $30(81.08 \%)$ males and 7 (18.91\%) females, age ranging from 22 to 73 years, with a mean age of $49.13 \pm 15$. Etiology of empyema was complicated parapneumonic effusion in 25 patients (67.5\%), tuberculosis in 10 patients (27.02\%), and malignancy in 2 patients (5.40\%). Treatment of multiloculated pleural infections by uniportal video-assisted medical thoracoscopy was successful in 33 patients (89.1\%); those patients did not require any further intervention. Among successful cases, 25 patients (75.75\%) showed complete resolution, and 8 patients (24.24\%) showed partial success. Four patients (10.81\%) required subsequent thoracotomy with decortication.
\end{abstract}

Conclusion: The conclusion of the present study is that uniportal video-assisted medical thoracoscopy is a safe, valuable, and effective tool in the management of multiloculated pleural infections.

Keywords: Thoracoscopy, Empyema, Pleura

\section{Background}

Pleural infection is a serious clinical problem that is associated with significant morbidity and variable mortality ranging from 2 to $30 \%$ [1]. Two main categories of pleural infections are recognized which are simple and complex or multiloculated [1].

Different etiologies may lead to the development of pleural infections; it can be either primary caused by pleuropulmonary inflammation or secondary to other causes, like postoperative complications, thoracic trauma, or extension of an inflammatory process in the neck or abdomen [2].

Correspondence: amr_shoukri@hotmail.com

Department of Chest Diseases, Faculty of Medicine, Ain Shams University, 43 ElMahrouky Street, Heliopolis, Cairo, Egypt
Management of pleural infection includes mainly drainage of the pus from the pleural cavity and treatment of the infection with antimicrobial agents [3].

Drainage procedures range from semi-invasive techniques such as therapeutic aspiration, tube thoracostomy, and intrapleural fibrinolytics to invasive interventions such as thoracoscopy, thoracotomy, or open drainage [4].

Complex or multiloculated pleural infection is a category that often requires invasive interventions; however, the best approach and the time of intervention are still debatable [5].

Medical thoracoscopy is nowadays an important diagnostic and therapeutic tool for pulmonologists. Management of pleural infection is considered one of the nonroutine and complex indications of this procedure, and

\section{Springer Open}

(ㅇ The Author(s). 2020 Open Access This article is licensed under a Creative Commons Attribution 4.0 International License, which permits use, sharing, adaptation, distribution and reproduction in any medium or format, as long as you give appropriate credit to the original author(s) and the source, provide a link to the Creative Commons licence, and indicate if changes were made. The images or other third party material in this article are included in the article's Creative Commons licence, unless indicated otherwise in a credit line to the material. If material is not included in the article's Creative Commons licence and your intended use is not permitted by statutory regulation or exceeds the permitted use, you will need to obtain permission directly from the copyright holder. To view a copy of this licence, visit http://creativecommons.org/licenses/by/4.0/. 
should be certainly performed by highly trained thoracoscopists [6,7].

\section{Methods}

This retrospective study was conducted in the Department of Pulmonary Medicine, Ain Shams University Hospitals, during a 4-year period (March 2012-March 2016).

\section{Inclusion criteria}

Review of the files of patients referred to our department with multiloculated pleural infection and treated with medical thoracoscopy.

Pleural infection was defined as frank pus detected on pleural tapping, with or without positive gram stain or bacteriological cultures.

All patients underwent chest radiograph, computed tomography of the chest, and chest ultrasonography.

All patients received empirical antibiotic regimen covering most of the probable germs that was modified later on according to the bacteriological results. Patient with tuberculosis received anti-tuberculous treatment.

The decision to use medical thoracoscopy was made after failure of conservative treatment with antibiotics and pleural aspiration.

Multiloculated pleural infection was identified by the presence of intrapleural septae with multiple loculations, and chest ultrasonography was the radiological method used to identify those cases.

\section{Exclusion criteria}

Patients with simple pleural infection (no multiple loculations detected by chest ultrasonography or organized empyema with fibrous thickening of the pleura detected by radiographic techniques) [8]. Patients with no follow up records for at least 6 months after hospital discharge were also excluded.

\section{Thoracoscopy procedure}

In all patients, fasting for at least $6 \mathrm{~h}$ is required with no other special preoperative preparation. The patients are monitored before and during the whole procedure (blood pressure, pulse, ECG, and pulse oximetry); the procedure was performed in lateral decubitus position with the affected side upward under general analgesia using a combination of inhalation anesthetic (isoflurane) and intravenous anesthetic (propofol).

Skin sterilization was performed followed by incision and blunt dissection in the appropriate intercostal space to access the pleural space; the choice for the site of entry was guided by chest ultrasonography performed on table in the lateral decubitus position. A $10-\mathrm{mm}$ trocar was then inserted, and a $0^{\circ}$ telescope was inserted through it and connected to a video camera; the pleural space was carefully inspected through the thoracoscope (TEKNO, Germany).

Fibrinous septae and adhesions were perforated, divided, and aspirated; forceps was used to remove debris (Figs. 1 and 2). At the end of the procedure, a chest drain (28F) was inserted and connected to underwater seal. IV antibiotics were given to all patients for at least 5 days following the procedure.

Successful treatment was defined by radiological improvement, that is consistent after month following chest tube removal, in the form of complete or partial resolution (reduction of the size of the pleural opacity to less than one third of the pleural space), with no need for further interventions or chest tube insertion, and evidence of clinical and laboratory improvements (improvements in body temperature, clinical picture, and inflammatory markers). Follow-up records were available for 6 months after hospital discharge, so patients who required any kind of later interventions were identified.

\section{Statistical analysis}

Quantitative data were represented as mean $( \pm \mathrm{SD})$, and qualitative data were represented as number and percentage. Data entry and statistical analysis were performed using (SPSS for Windows, version 20.0; SPSS Inc., Chicago, IL, USA).

\section{Results}

This retrospective study included 37 patients with multiloculated pleural infection, $30(81.08 \%)$ patients were males, and 7 (18.91\%) were females. Age of the included patients ranged from 22 to 73 years, with a mean age of $49.13 \pm 15$.

The etiology of empyema was complicated parapneumonic effusion in 25 patients (67.5\%), tuberculosis in 10 patients $(27.02 \%)$, and malignancy in 2 patients $(5.40 \%)$

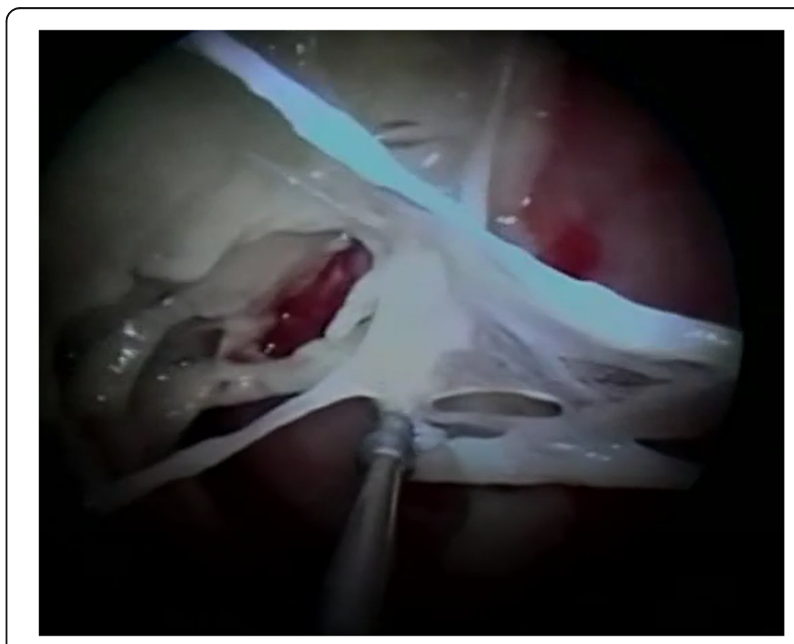

Fig. 1 Biopsy forceps used to cut intrapleural adhesions 


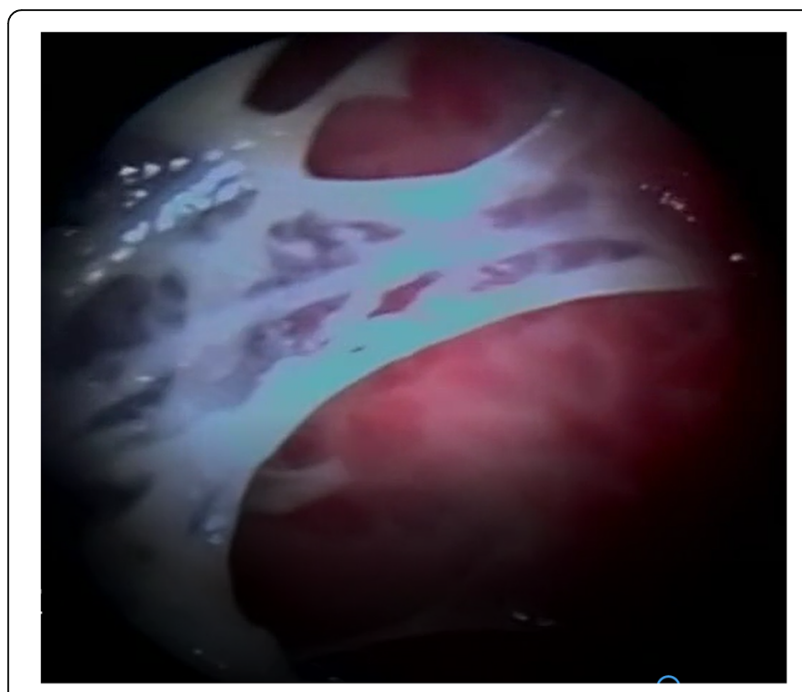

Fig. 2 Encysted empyema with adhesions between visceral and parietal pleura

which is proved to be pleural mesothelioma (Table 1). Microbiological culture results revealed no detected germs in most of the patients (Table 2).

Uniportal video-assisted medical thoracoscopy was performed to all patients, ultrasound guidance to identify the best port of entry was applied in all cases.

The length of the procedure ranged from 45 to 72 min, with a mean length of $53 \pm 11.6$.

Chest drain was inserted at the end of the procedure, and the duration of drainage ranged from 7 to 12 days with a mean duration of $8.83 \pm 1.66$.

Treatment of multiloculated pleural infection by medical thoracoscopy was successful in 33 patients (89.1\%), and 25 patients (67.5\%) showed complete resolution of the pleural fluid on further radiographic assessment performed 1 month after the chest tube removal, and 8 patients (21.6\%) showed partial success, and none of the successful cases required any further surgical interventions or chest tube

Table 1 Sociodemographic data and etiology of pleural infection in the studied patients $(n=37)$

\begin{tabular}{ll}
\hline Variables & $N(\%)=37$ \\
\hline Age (years) & \\
Mean \pm SD & $49.13 \pm 15$ \\
Range & $22-73$ \\
Gender & \\
Male & $30(81.08 \%)$ \\
Female & $7(18.91 \%)$ \\
Etiology & \\
Parapneumonic & $25(67.5 \%)$ \\
Tuberculosis & $10(27.02 \%)$ \\
Malignancy & $2(5.40 \%)$ \\
\hline
\end{tabular}

Table 2 Microbiological diagnosis of pleural fluid in studied patients $(n=37)$

\begin{tabular}{ll}
\hline Microbiological organisms & Number (\%) \\
\hline Gram-positive organisms (streptococcus) & $1(2.7 \%)$ \\
Gram-positive organisms (staphylococcus aureus) & $1(2.7 \%)$ \\
Gram-negative organisms & $3(8.10 \%)$ \\
No growth & $19(51.35 \%)$ \\
Anaerobic organisms & $1(2.7 \%)$ \\
Mixed germs & $2(5.4 \%)$ \\
Tuberculosis & $10(27.02 \%)$ \\
\hline
\end{tabular}

insertion in the follow-up period (Table 3). Four patients (10.81\%) required subsequent thoracotomy with decortication due to persistent sizable empyema (Table 3).

No recorded mortality, and complications related to the procedure occurred in 3 patients (8.10\%), 2 patients developed prolonged air leak for 4 to 6 days, and 1 patient had subcutaneous emphysema.

All complications were spontaneously resolved and did not affect the final outcome.

\section{Discussion}

The role of medical thoracoscopy in the management of pleural infection is gaining more and more interests, and it is able to efficiently breakdown adhesions and septations, and to remove fibrin debris from the pleural cavity. It is considered less invasive than other surgical procedures [9].

This retrospective study reviewed the charts of $37 \mathrm{pa}-$ tients with multiloculated pleural infection, for whom uniportal video-assisted medical thoracoscopy was performed in order to manage their condition; all our patients had their procedure done under guidance of chest ultrasonography, which is proved to better identify the best point of entry, lowers the risk of complications, and shortens the length of the procedure [10].

The etiology of pleural infection in most of the patients in this series was complicated parapneumonic effusion (67.5\%), and other etiologies included tuberculosis (27.02\%), and pleural mesothelioma (5.40\%).

Apart from the 10 cases $(27.02 \%)$ who were diagnosed with tuberculosis, the microbiological profile of the studied patients revealed gram-positive germs in 2 cases

Table 3 Outcome of multiloculated pleural infection after treatment with medical thoracoscopy in the studied patients ( $N$ $=37$ )

\begin{tabular}{ll}
\hline Outcome & Number (\%) \\
\hline Complete resolution & $25(67.5 \%)$ \\
Partial resolution & $8(21.6 \%)$ \\
Failure (need for further surgical intervention) & $4(10.81 \%)$ \\
\hline
\end{tabular}


(5.4\%), gram-negative germs in 3 cases (8.1\%), anaerobic organisms in one patient (2.7\%), mixed germs in 2 cases (5.4\%), while no germs have been detected in culture and sensitivity in most of the patients (51.35\%). These low-yield results for cultures are mostly due to antibiotics used by those patients prior to sampling, and it was demonstrated in a previous study [11].

It was previously recommended in the literature to use medical thoracoscopy early in the course of empyema [12]. This present retrospective study was mainly focused on multiloculated pleural infection, and it showed that uniportal video-assisted medical thoracoscopy was successful in the management of 33 out of 37 patients (89.1\%). Among those patients, $75.75 \%$ showed complete resolution of the pleural fluid, and $24.4 \%$ showed partial resolution with residual pleural thickening. None of them required any further surgical interventions.

Our results are in accordance with previous studies, and Ravaglia et al. [13] have demonstrated successful management of multiloculated pleural infection using medical thoracoscopy in $91.7 \%$. Another study [14] reported successful treatment in $91 \%$ of the cases of multiloculated pleural infection with medical thoracoscopy, but they stated $49 \%$ of the patients received post interventional intrapleural fibrinolytics, which was not applied in any of our patients.

There was no recorded mortality. Complications were minimal, and it occurred in only 3 patients $(8.10 \%)$ and was resolved spontaneously. This agrees with the fact that medical thoracoscopy is a safe procedure, and other studies have confirmed the occurrence of minimal complications in the management of multiloculated pleural infection with medical thoracoscopy $[13,14]$.

\section{Conclusion}

The conclusion of the present study is that uniportal video-assisted medical thoracoscopy is a safe, valuable, and effective tool in the management of multiloculated pleural infection.

\section{Acknowledgements}

None

Fundingn

None

\section{Author's contributions}

AS contributed in concept, design, data acquisition, data analysis, statistical analysis, manuscript preparation, editing, and review. The author have read and approved the manuscript.

\section{Availability of data and materials}

The datasets generated during and/or analyzed during the current study are available from the corresponding author on reasonable request.

Ethics approval and consent to participate

Ethics approval was obtained from the Ain Shams University, Faculty of Medicine research ethics committee (FWA00018475). Written informed consent signed by each patient to use his data.
Consent for publication

Consent was obtained from each participant to publish his data collected in the study.

\section{Competing interests}

None

Received: 7 May 2020 Accepted: 27 July 2020

Published online: 12 August 2020

References

1. Heffner JE (1996) Diagnosis and management of thoracic empyemas. Curr Opin Pulm Med 2:198-205

2. Mandal AK, Thadepalli H, Mandal AK, Chettipally U (1998) Outcome of primary empyema thoracis: therapeutic and microbiologic aspects. Ann Thorac Surg 66:1782-1786

3. Davies CW, Gleeson FV, Davies RJ (2003) BTS guidelines for the management of pleural infection. Thorax 58(Suppl 2):ii18-ii28

4. Sahn SA (2007) Diagnosis and management of parapneumonic effusions and empyema. Clin Infect Dis 45:1480-1486

5. Light RW (1995) A new classification of parapneumonic effusions and empyema. Chest 108:299-301

6. Loddenkemper R (1998) Thoracoscopy: state of the art. Eur Respir J 11:213-221

7. Shoukri A (2013) Medical thoracoscopy: past, present, and future. Egyptian J Bronchol 7:50-52

8. Neville E, Buchanan DR (2005) Thoracoscopy for physicians; a practical guide. Arnold Publisher, London, pp 57-70

9. Rahman NM, Ali NJ, Brown G, Chapman SJ, Davies RJ, Downer NJ, BTS Pleural Disease Guideline Group et al (2010) Thorax 65:ii54-ii60

10. Shoukri A (2015) Ultrasound-assisted medical thoracoscopy. Egyptian J Bronchol 9:92-95

11. Jimenez D, Diaz G, Garcia-Rull S, Vidal R, Sueiro A, Light RW (2006) Routine use of pleural fluid cultures. Are they indicated?: limited yield, minimal impact on treatment decisions. Resp Med 100:2048-2052

12. Tassi GF, Davies RJ, Noppen M (2006) Advanced techniques in medical thoracoscopy. Eur Respir J 28:1051-1059

13. Ravaglia C, Gurioli C, Tomassetti S, Casoni GL, Romagnoli M, Gurioli C et al (2012) Is medical thoracoscopy efficient in the management of multiloculated and organized thoracic empyema? Respiration 84:219-224

14. Brutsche MH, Tassi GF, Györik S, Gökcimen M, Renard C, Marchetti GP et al (2005) Treatment of sonographically stratified multiloculated thoracic empyema by medical thoracoscopy. Chest 128:3303-3309

\section{Publisher's Note}

Springer Nature remains neutral with regard to jurisdictional claims in published maps and institutional affiliations.

\section{Submit your manuscript to a SpringerOpen ${ }^{\circ}$ journal and benefit from:}

- Convenient online submission

- Rigorous peer review

- Open access: articles freely available online

High visibility within the field

- Retaining the copyright to your article

Submit your next manuscript at $>$ springeropen.com 